Working Copy (for Educational/Research use only). To cite this work:

F. P. Brito, Jorge Martins, L.M. Goncalves, Nuno Antunes, Diogo Sousa, "Influence of Heat Pipe

Operating Temperature on Exhaust Heat Thermoelectric Generation", SAE International Journal of

Passenger Cars - Mechanical Systems 6(2):2013 652-664, DOI: 10.4271/2013-01-0559

\title{
Influence of Heat Pipe Operating Temperature on Exhaust Heat Thermoelectric Generation
}

\author{
F P Brito, J. Martins, L M Goncalves, D Sousa, N Antunes \\ Universidade do Minho, Guimaraes, Portugal
}

Copyright () 2013 SAE International

\section{ABSTRACT}

Increasingly stringent targets on energy efficiency and emissions, as well as growing vehicle electrification are making attractive the electric recovery of the energy normally wasted through the tailpipe of Internal Combustion Engines. Recent developments in thermoelectrics (TE) may soon make them a viable solution for such applications [1].

This team has been exploring the potential of using TE modules in combination with variable conductance heat pipes for transferring the exhaust heat to the generator with very low thermal resistance and at a constant, prescribed temperature. This passive temperature control eliminates the need for bypass systems in the event of temperature overshoots.

The operating temperature of a generator should be as high as possible in order to maximize the Seebeck effect. However, currently available modules are temperature limited.

Moreover, the higher the HP temperature the less the usable thermal power at the exhaust will be (heat can only be transferred to from a hotter to a colder body).

The present work assesses both theoretically and experimentally the influence of the HP temperature in the electric output of a thermoelectric generator. A small diesel engine and a generator were tested and it was found that a high HP operating temperature is only limitative for performance in the cases where low exhaust temperature and low engine power are present. In those cases it is possible to estimate an optimal HP temperature in order to maximize power output. The combined use of Seebeck modules and heat pipes was found to be highly advantageous in various ways.

\section{INTRODUCTION}

The harvesting of the wasted energy in Internal Combustion Engines (ICE) is now becoming more and more attractive as fuel economy and emissions targets [2;3] are getting evermore challenging for automotive industry OEMs. In fact, over one third of the energy content of the fuel is normally wasted through the tailpipe of the ICE [4;5], with a similar amount being lost in other ways, namely the cooling system. In comparison to the cooling heat, the exhaust energy has a much better recovery potential due to its high temperature level.

Energy waste may be reduced firstly by improving the thermal efficiency of the ICE with strategies such as over-expansion, as explored by the team $[6 ; 7]$ or by converting it into electricity, something increasingly attractive given vehicle electrification trends.

Electric turbo-charging/compounding, Organic Rankine Cycle (ORC) turbines [8;9] and Thermoelectric Generators (TEGs) based on the Seebeck effect [1] have been tested in heavy duty applications in the past. ORCs have the highest recovery potential [9] but are still difficult to downsize for light duty vehicle applications [10].

Despite its still low efficiency, state-of-the-art TE modules exploring phenomena such as quantum confinement are claiming efficiencies above $10 \%$ [11]. TEGs are reliable as they don't have moving parts and they are very small in volume. Moreover, they currently stand as the only practical option for low power waste heat recovery applications since they are intrinsically scalable. Major OEMs like Honda [12] and BMW [13] have been testing this technology, some with targets of 5\% improvement in fuel economy.

But the currently most significant obstacles for TEG adoption in exhaust applications are their limitations in operating temperature, power density and cost [10]. The current power density and cost restraints of TEGs may soon be overcome by the use of low thickness TE modules combined with very low thermal resistance heat paths [14]. Solutions for controlling the operating temperature of TEGs with low thermal resistance and high reliability (no moving parts) have been proposed by the team using heat-pipes. This included both theoretical and experimental work with several proof-ofconcept prototypes [15-18]. This solution avoids the use of by-

Page 1 of 13 
pass systems as the source heat is converted to the required temperature level.

The use of a phase changing fluid contained within Heat Pipes (HP) to transfer the heat from the exhaust gases to the thermoelectric devices is convenient in several ways [19]. On one hand, Boiling and Condensation are among the most effective heat transfer mechanisms available. Additionally, the possibility of regulating the operating temperature of the HP (the boiling point of its fluid) provides passive protection to the system in terms of overheating, thus eliminating the need for wastegates/bypass valves.

Ideally, the heat directed to the TEG should display the highest possible temperature that the modules can withstand in order to maximize the Seebeck Effect (voltage generated increases with the increase of the temperature differential across the thickness of the TEG modules). However, currently available modules are temperature limited. Furthermore, the temperature of the HP fluid has to be suitable for the exhaust gas conditions. Too high and the temperature difference between gases (at low power conditions) and HP will be too small to provide enough power. Too low and the TEG efficiency will drop below usefulness. For each exhaust condition there will be an optimal HP working temperature.

Previous work published by the group has illustrated the potential of TEGs with HP assist by testing several proof-ofconcept prototypes. The present work assesses the influence of HP temperature on TEG performance both theoretically and experimentally.

\section{Heat Pipes}

A Heat Pipe (HP) is a thermal device with an extraordinary degree of heat transfer potential, as it uses one of the most efficient modes of heat transfer, the phase change [19]. In short, a heat pipe (Fig. 1) is a tube where in one extremity a liquid (can be water) boils and on the other end it condenses, transferring an enormous amount of heat from the boiling end to the condensing end. A large flow of fluid travels in vapor form (from vaporization to condensation ends) through the inside of the pipe and in liquid form, by gravity, attached to the walls.

The HP depicted in Fig.1 has only one fluid, in vapor and in liquid form, obviously at saturation conditions. This means that the pressure and the temperature will change according to the outside temperature and according to the thermal power it is subjected to. Therefore, it is not possible to control the temperature at which the heat transfer will occur because increased vapor generation will easily raise the inner pressure and thus also raise the saturation temperature. For that we need to control the HP pressure independently of its heat flux.

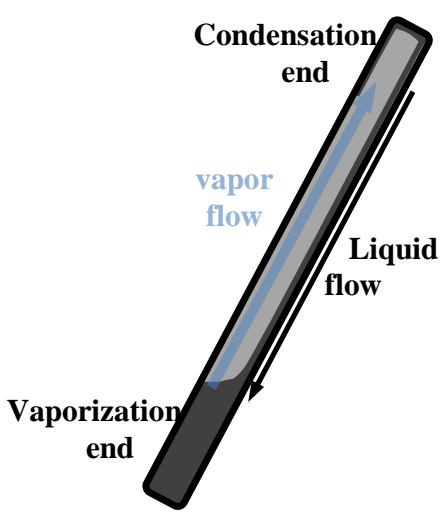

Figure 1. Working principle of a basic Heat Pipe

This device is called the Variable Conductance Heat Pipe (VCHP), and it incorporates an expansion tank as well as a non-condensable gas in its interior at a prescribed pressure. The expansion tank has the ability of accommodating variable vapor content during variable load operation without significant pressure increase. Now, if the non condensable gas pressure is kept constant, so will be the phase-change temperature of the working fluid. This latter temperature will be the HP temperature. With this appliance it is possible to accomplish the goal of limiting the temperature at which the heat is supplied to the TEG and tune this temperature to an optimum. The VCHP proposed in this work is of this type.

Fig. 2 displays the comparison of Standard and Variable Conductance Heat Pipes under variable thermal load.

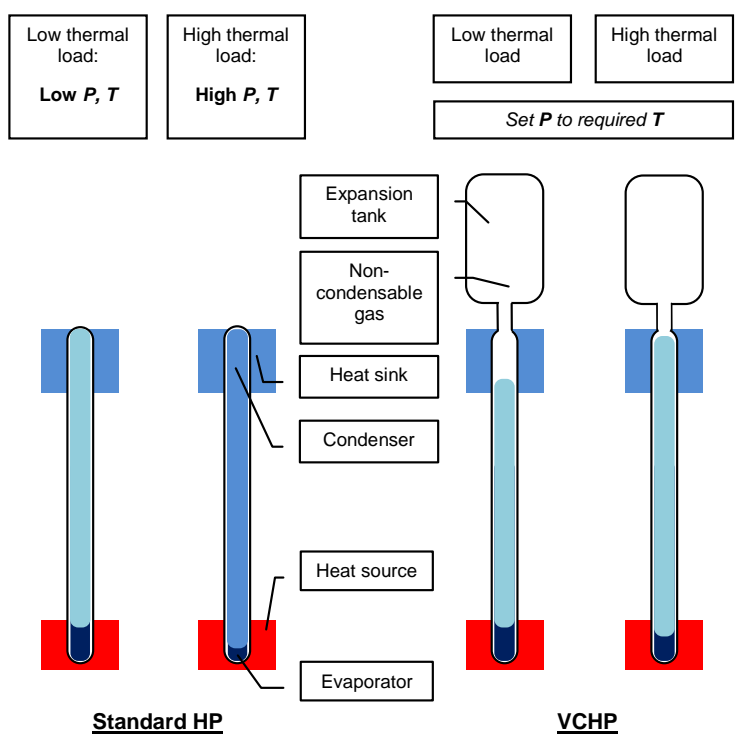

Figure 2. Comparison of Standard and Variable Conductance Heat Pipes under variable thermal load

The Variable Conductance Heat Pipe owes its name to the fact that the active area of the condenser (the area reached by the vapor) will vary according to the thermal load. In fact, as more 
thermal power is available, a higher amount of vapor will be generated. This vapor mass will push the gas further up, taking its place pushing it out of the condenser region, and therefore will reach a bigger area of the condenser. Under these conditions, the active area of the condenser will vary according to thermal load providing the analogous of a variable conductance medium.

Additionally, it would possible to envisage a device with actively controllable pressure by means of a pressure adjustable membrane bladder, therefore allowing different working temperatures. This may be interesting to enhance the heat transfer levels for different exhaust conditions (different engine loads and speeds) but would increase system complexity. If the temperature for the phase change is set at the maximum (allowed by the TEGs), then the heat transfer will be very limited at low exhaust temperatures. It is therefore advisable to find the idleal HP temperature so as to maximize electric output. After having illustrated the potential of using temperature controlled thermoelectric generation with heat pipes in previous works, the present work explores precisely the issue of optimal heat transfer temperature in such systems.

The use of a very small $10 \mathrm{hp}$ Diesel engine with a generator with only 12 thermoelectric modules illustrates the scalability of this type of technology. Naturally, bigger engines and generators will be likely used in other applications of this technology in the future.

\section{EXPERIMENTAL PROCEDURE}

A proof-of-concept model of a VCHP device has been built in order to assess the potential for heat recovery from the exhaust system of a small Internal Combustion Engine (ICE). It is an evolution of a previous model studied before [16].

The evaporator end of the VCHP is immersed in the exhaust stream of a small single-cylinder Diesel engine. This evaporator consists of a series of finned copper pipes (see Fig.3). We used the actual pipework from a combustion chamber of a small hot water boiler. It has 7 fins per centimeter. This system is seen at the bottom of the global apparatus seen further ahead in Fig 6 .

As seen in Fig. 3, the evaporator has 6 finned pipes that are all interconnected at the bottom (to equalize liquid level), with 8 $\mathrm{mm}$ outer diameter and $0.5 \mathrm{~mm}$ of thickness.

These 6 copper pipes are connected to three upper copper blocks, acting as condensers. The vapor generated at the evaporator will rise and condense at the blocks, falling back (due to gravity) to the evaporator. The HP fluid used was water, filling the length of the evaporator pipes that is immersed in the exhaust gas flow. Using water as working fluid is recommended only for mild temperatures since increasingly high pressures are needed for higher HP operating temperatures (for instance, obtaining a $200{ }^{\circ} \mathrm{C}$ water boiling temperature would require pressures in excess of 15 bar). The authors have tested previously other fluids besides water. Namely, a fluid called DOWTHERM A was used for the higher temperature range [16]. This fluid has a phase change temperature around $250^{\circ} \mathrm{C}$ at atmospheric pressure. Fluids recommended for other temperature ranges are proposed in [19].

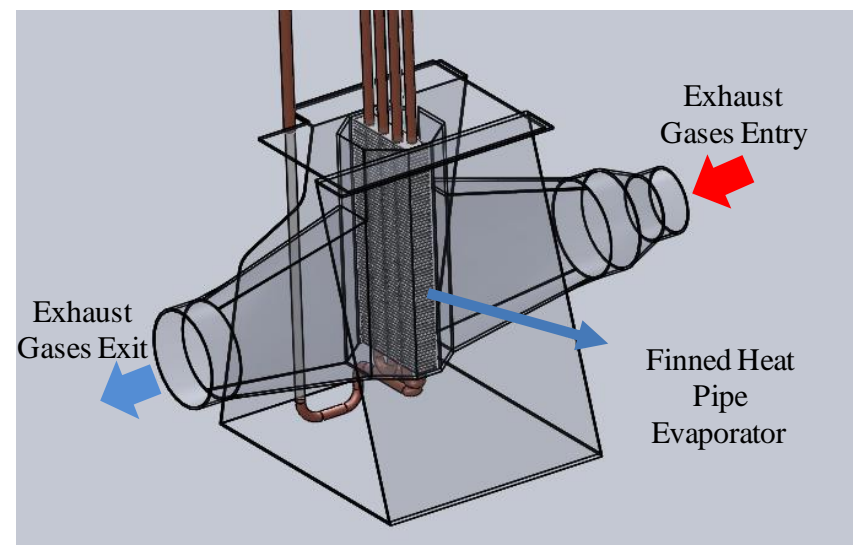

Figure 3. Drawing of the exhaust gases duct with the HP Evaporator inside.

No wick covering the inner HP surface was deemed as necessary in this phase, as the HP can operate solely on gravity. Consequently, the HP heat exchanger solution adopted does not pose the cost issues frequently associated with the more customized wicked HPs like those found in aerospace applications [19].

TEG modules were placed on the outer surface of these condenser blocks, "sandwiched" between them and the water cooling ducts. These condenser blocks, shown in Fig. 4, are $20 \mathrm{~mm}$ thick solid copper blocks with an area that fits two vertically aligned thermoelectric modules (RS Amidata ref. 6937116 with dimensions $62 \times 62 \times 5.3 \mathrm{~mm}^{3}$ ) on each face. The blocks were drilled with two different diameter wholes, as shown. The bottom of the first block has six $8 \mathrm{~mm}$ holes, where the 6 heat pipes have been attached. These six $8 \mathrm{~mm}$ holes are extend up to two thirds of the length of the block and are intercepted by three $16 \mathrm{~mm}$ holes drilled from the top of the block down to a depth of two thirds of the total block height. The condensation of the working fluid occurs on these inner surfaces.

Of course, an optimized commercial version of the concept need not use expensive bulk copper (it has been used here to easily obtain low thermal resistances). The aim will be to increase the condensing area and reduce thermal resistance (either obtained with high conductive materials or low thickness ones). 

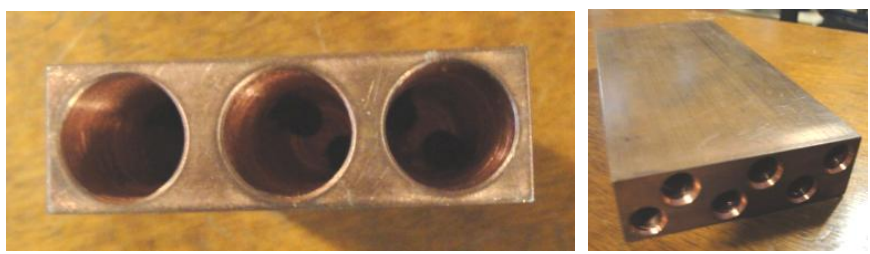

\section{Figure 4. Upper view (left) and lower view (right) of the HP condenser blocks}

On the outer (cold) face of the TEGs water ducts were placed, as shown in Fig. 5. These were also made from solid copper blocks ( $15 \mathrm{~mm}$ thick) drilled with seven $6 \mathrm{~mm}$ holes, through where the cooling water would flow. To maximize the convective heat transfer the contiguous channels were connected in zig-zag in a series configuration so that water speed and turbulence could be maximized.

Again, this proof-of-concept system could be optimized for the commercial application by using less bulk materials, lower thicknesses and wider exchange areas.

Sharing the engine's cooling system for cooling the modules may not be a good solution since its temperature is too high (loss of temperature differential). However, a dedicated low temperature cooling system does not seem to be ideal either, as it could have some energy consumption and would add complexity to the system. This issue has still not been addressed in the current work, but some passive cooling system would be envisaged for future work. This could consist on a finned air cooled heat sink in contact with the vehicle's external air flow. Even better, a heat pipe with an externally finned heat sink at the HP condenser.

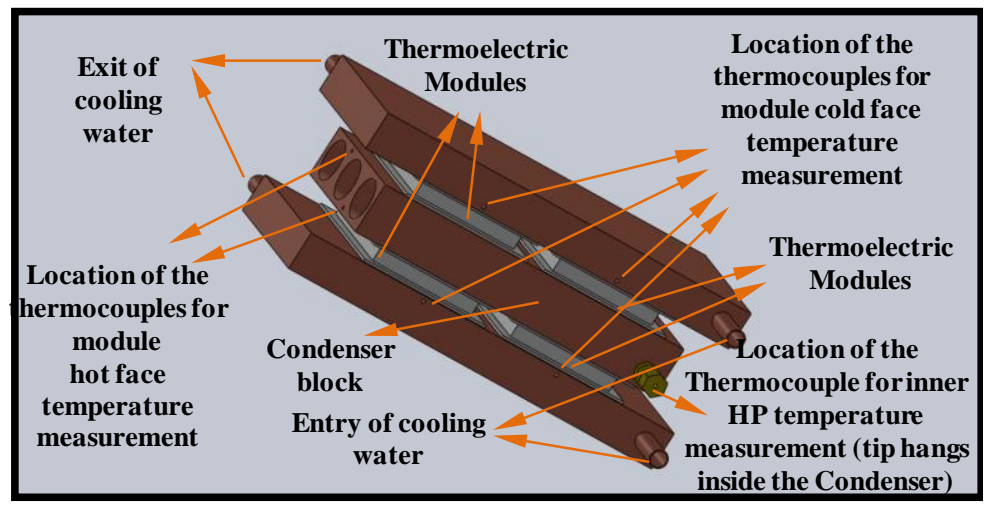

\section{Figure 5. One of the three HP condenser blocks each one attached with modules on both sides and external cooling ducts.}

Fig. 6 shows a global view of the apparatus (the complete system is seen in Fig. 8). Comparing with the outline of Fig. 2 the heat source is the exhaust gas flow that crosses the evaporator as seen previously in Fig. 3. The condenser consists on the group of three blocks, each with 4 thermoelectric modules attached. The face of the modules attached to the condenser blocks (called the hot face of the modules) is the heat sink of the HP (the medium through which the heat is retrieved from the system). On the other hand, the heat absorbed by the modules is subsequently channeled to the exterior by the cooling ducts that are attached to the outer face (called the cold face) of these same modules, as depicted in Fig. 5. For clarity these ducts are missing in Fig 6 so that the modules may be seen.

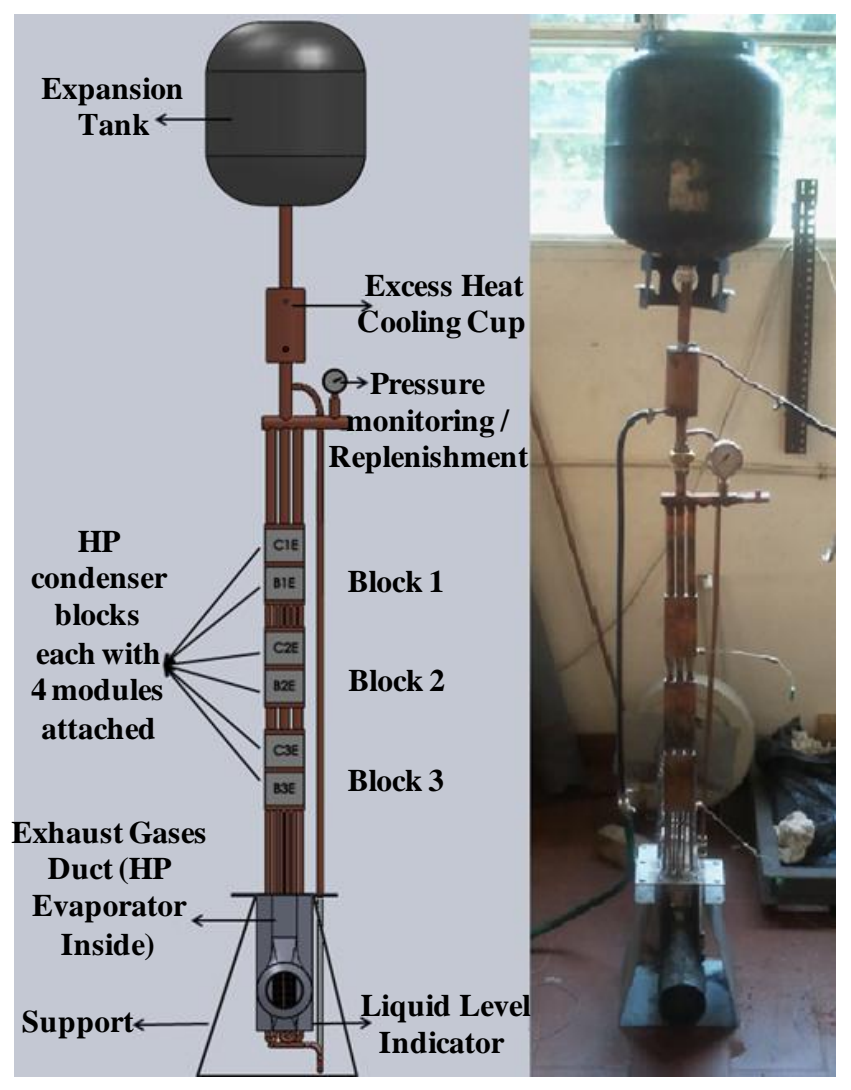

Figure 6. Design and photograph of the apparatus

Three $16 \mathrm{~mm}$ copper tubes make the connection between Block 3 to 2, and the connection from that block to Block 1 (the top block) is again made by six $8 \mathrm{~mm}$ tubes (Fig. 6).

A collector, located at the top of the system, connects the pipes from the top block (Block 3 ) to a $20 \mathrm{~L}$ expansion tank that ensures constant pressure (and thus operating temperature) of the system irrespective of load. Since this is still a proof-of-concept apparatus no calculations to optimize the tank capacity have been made, but the results confirmed the isothermal operation of the system. The Clausius Clapeyron relation (which relates pressure, temperature and volume differentials for vapor) could be used to do this.

In the event of an excessive load the vapor region will expand extending beyond the condenser blocks. To avoid the risk of evaporator dry out during these high power events, a cooling cup (a water cooled concentric tube condenser) has been added between the collector and the expansion tank. This 
simple artifact ensures that the excess vapor that moves above the condenser blocks effectively condenses even during excess load events.

There is an external tube, connecting the collector to the evaporator, including a glass tube used for visualization of the liquid level during operation. Although it resembles a two phase thermosiphon loop, its only purpose is to measure the liquid level at.

Several sleeved type-K thermocouples (with $\pm 0.5^{\circ} \mathrm{C}$ uncertainty when measured with data acquisition system NI 4350 with 24 bit resolution) were used for temperature measurement. They were placed in various locations to measure temperature and determining heat transfer rates within the apparatus. Namely, thermocouples were placed at exhaust entry/exit, at the modules' faces, inside the heat pipes (in the midst of the vapor) and along the cooling circuit at the several entries/exits of the blocks and excess heat cup. This was made in order to measure the thermal power reaching the coolant coming from each block/cup.

Voltage measurements were performed with 12 bit NI USB 6009 data acquisition cards. The accuracy of these cards is $15 \mathrm{mV}$ according to the manufacturer. Both open and closed circuit voltages were measured in the modules.

The water cooling flow rate was measured periodically with a graduated glass container and kept constant at $112 \pm 2 \mathrm{~L} / \mathrm{h}$. The thermal power is calculated from the water's mass flow, specific heat $c_{p}$ and the temperature differential $T_{\text {in }}-T_{\text {out }}$. Therefore, for water temperature differences around $10{ }^{\circ} \mathrm{C}$ (which corresponds to $1.3 \mathrm{~kW}$ power) the maximum error for the thermal power will less than $\pm 7 \%$.

The tests were performed with an Yanmar single-cylinder Diesel engine (Fig.7) with characteristics listed in Table 1. It has a maximum power of $10 \mathrm{hp}(7.4 \mathrm{~kW})$.

Because of laboratory conditions, the distance between the engine and the apparatus was rather large $(\sim 3 \mathrm{~m})$, so the temperature of exhaust gases decreased significantly between the engine and the TEG generator.

\section{Table 1. Engine Characteristics}

\begin{tabular}{|l|l|}
\hline Model & Yanmar L100N \\
\hline Type & Diesel \\
\hline Injection type & Direct Injection (mech.) \\
\hline Displacement & $435 \mathrm{cc}$ \\
\hline Bore & $86 \mathrm{~mm}$ \\
\hline Stroke & $75 \mathrm{~mm}$ \\
\hline Continuous rated Power & $9 \mathrm{hp}(6.6 \mathrm{~kW}) @ 3600 \mathrm{rpm}$ \\
\hline Maximum rated Power & $10 \mathrm{hp}(7.4 \mathrm{~kW}) @ 3600$ \\
\hline Cooling type & Air cooled \\
\hline
\end{tabular}

Page 5 of 13

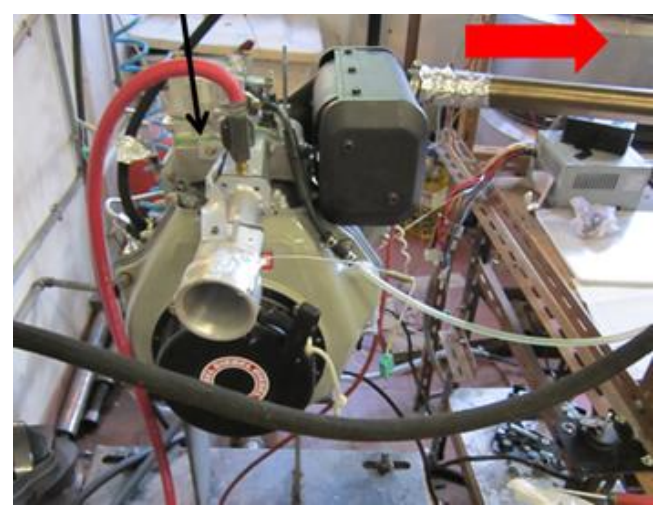

Figure 7. Diesel engine used for the experiments

The overall view of the apparatus under operation with insulation can be seen in Fig.8.

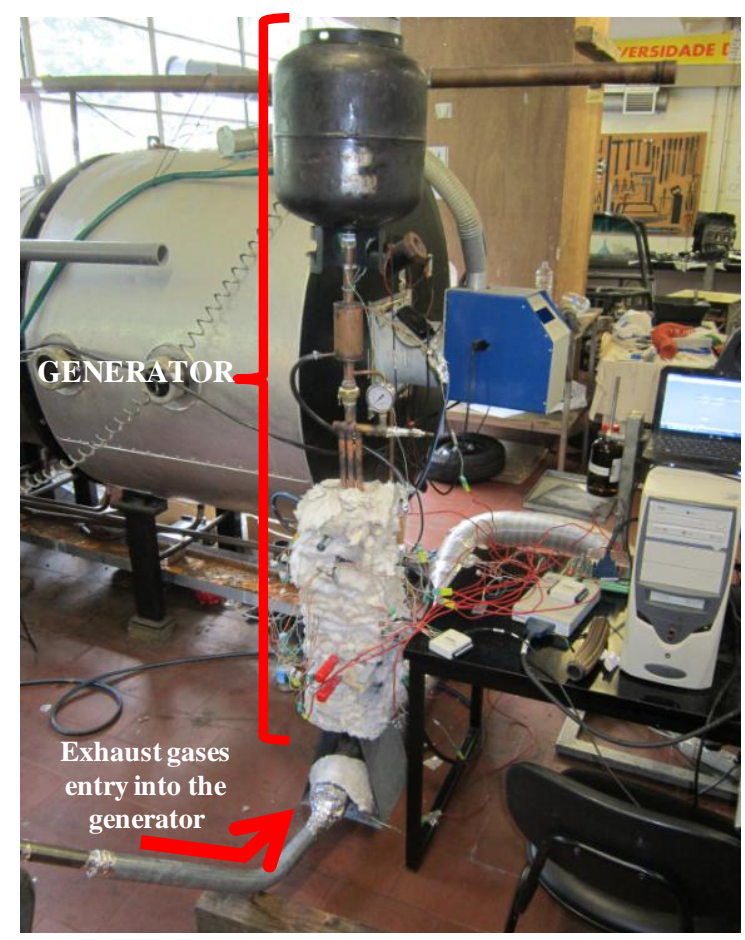

Figure 8. Apparatus connected to the exhaust of the engine

\section{$\underline{\text { RESULTS }}$}

\section{Theoretical analysis}

Prior to presenting the experimental results it is possible to estimate, for a given exhaust temperature, $T_{\text {exhaust }}$ and mass flow rate of gases, $\dot{m}_{\text {exhaust }}$ the maximum possible electric power generated as function of the Heat Pipe temperature, $T_{H P}$. This would happen if all the available thermal power of the exhaust gases is absorbed by the system. Under such 
conditions the exhaust temperature would leave the system with temperature $T_{H P}$ (it is not possible to transfer heat from a cold to a hot medium). Therefore, the maximum available thermal power, or in other words, the maximum absorbable exhaust thermal power, will be given by the following expression:

$P_{t_{-} \text {available }}=\dot{m}_{\text {exhaust }} \cdot c_{p_{-} \text {exh }} \cdot\left(T_{\text {exhaust }}-T_{H P}\right)$

Therefore, for a given exhaust system, the higher the HP temperature, the lower will be the available thermal power.

For a real case, only a fraction of the available thermal power will actually be captured by the system due to thermal resistances. This fraction has been designated here the thermal efficiency of the system, $\eta_{t}$

$\eta_{t}=\frac{P_{t}}{P_{t_{-} \text {available }}}$

The next step is to infer the amount of thermal power that is actually converted into electric thermal power. The total electric power output due to the Seebeck effect, $P_{e}$, will be a function of the total voltage generated, as well as of the internal and load resistances. The open circuit voltage generated by Seebeck effect, $V_{o}$, will be simply the multiplication of the Seebeck coefficient, $\alpha$, by the temperature difference between the two faces (called hot and cold faces) of the modules, and finally multiplied by the total number of modules, $n$, which will typically be connected in series $\left(V_{0}=\alpha \cdot\left(T_{H}-T_{c}\right) \cdot n\right)$.

It has been proven that the electric power output can be maximized if the load resistance equals the total internal resistance of the generator, $n \cdot R_{i}$ [20], with $\mathrm{Ri}$ being the internal resistance of a thermoelectric module, which can vary with temperature. These conditions may be achieved by using a Maximum Power Point Tracking (MPPT) device. The theoretical maximum electric power output, $P_{e_{-} \max }$ would therefore be obtained with a thermally optimized system (in the limit, with negligible thermal resistance). This would mean that the hot and cold faces of the modules would be virtually equal to the heat source and heat sink temperatures. For a system with a Heat Pipe regulating the heat source temperature to $T_{H P}$ and a heat sink consisting of a circuit of liquid with average temperature $T_{\text {coolant_avg }}$ cooling the cold face of the modules, the theoretical maximum electric power output, $P_{e_{-} \max }$ would therefore be the following:

$$
P_{e \_ \text {max }}=\frac{\left[n \cdot \alpha \cdot\left(T_{H P}-T_{\text {coolant_avg }}\right)\right]^{2}}{4 \cdot n \cdot R_{i}}
$$

Now the average coolant temperature, $T_{\text {coolant_avg }}$ is itself a function of the thermal power crossing all the modules (the fluid increases its temperature as it cools down the modules):

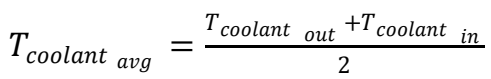

$$
T_{\text {coolant avg }}=T_{\text {coolant_in }}+\frac{P_{t}}{2 \dot{m}_{\text {coolant }} c_{p_{-} \text {cool }}}
$$

The electric efficiency, $\eta_{e}$ is defined as follows:

$\eta_{e}=\frac{P_{e}}{P_{t}}$

If $\eta_{e}$ is measured experimentally as a function of the temperature differential $\left(T_{H P}-T_{\text {coolant_avg }}\right)$, it can be used to estimate the electric output as a function of the thermal power crossing the system. This relation between $\eta_{e}$ and $\left(T_{H P}-\right.$ $\left.T_{\text {coolant_avg }}\right)$ has been inferred from the experimental results obtained in the present work and is presented in eq. 10 at the end of the results section.

As an upper limit, all the available thermal power would be channeled through the system and the electric output would therefore be:

$P_{e_{-} \max }=\eta_{e} \cdot P_{t_{-} \text {available }}$

It is interesting to plot the results corresponding to this ideal situation because it illustrates the upper limit of the electric output that a system like this one could possibly yield if optimized. Considering the present case, where $\dot{m}_{\text {exhaust }}$ was estimated to be typically around $0.15 \mathrm{~kg} / \mathrm{s}$, with the specific heat of the exhaust gases, $c_{p_{-} \text {exh }}$ being around $1000 \mathrm{~J} / \mathrm{kgK}$ and the coolant flow, $\dot{m}_{\text {coolant }}$ being $0.031 \mathrm{~kg} / \mathrm{s}$, a plot was made for these conditions and displayed in Fig. 9. The exhaust temperature range encompasses typical Diesel exhaust temperatures, which are normally lower than those of Spark Ignition Engines. The range of HP temperatures was extended slightly beyond the maximum of the $600{ }^{\circ} \mathrm{C}$ condition. It is also important to bear in mind that current commercially available modules typically display low maximum operating temperatures.

It can be seen that for each exhaust temperature there will be a HP temperature that optimizes the electric output. For the conditions tested (exhaust temperature typically between $250{ }^{\circ} \mathrm{C}$ and $300{ }^{\circ} \mathrm{C}$ ) the ideal $\mathrm{HP}$ temperature is around $130{ }^{\circ} \mathrm{C}$. The trends of the curves can be easily explained. On one hand, the higher the exhaust temperature, the higher will be the electric output (recall eq. 1) because the available thermal power is higher. On the other hand, the higher the HP temperature, the lower will be the available thermal power (recall eq. 1). This has to do with the second law of thermodynamics. In fact, it is impossible for the heat pipe to absorb further heat from the exhaust gases once their temperature has fallen close to the HP temperature (heat transfer always occurs from a hotter to a colder medium, never the opposite). It is therefore easy to infer that the lower the exhaust temperature (for a given mass flow of gases) the lower will be the optimum HP temperature.

Page 6 of 13 


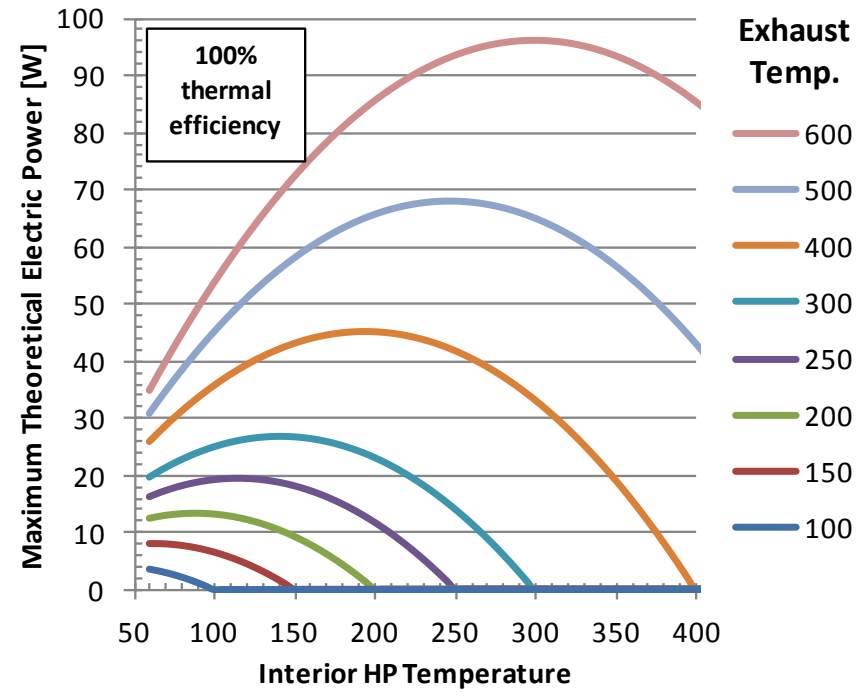

Figure 9. Electric power generated by a system with $100 \%$ thermal efficiency, as a function of HP temperature and Exhaust temperature

Now, if the thermal load is bigger for the same exhaust temperature (that is, if a higher mass flow of gases exists) it can be said with some confidence that the optimum HP temperature will also be higher. This has not been simulated here, but looking at eq. 1 it is easily understandable that the available thermal load under these conditions will also increase (due to a higher $\dot{m}_{\text {exhaust }}$ ) and allow a higher HP temperature.

Now considering a more realistic situation where only a fraction $\eta_{t}$ of the available heat is channeled into the system, the following equation applies:

$P_{e}=\eta_{e} \cdot P_{t}=\eta_{e} \cdot \eta_{t} \cdot P_{t_{-} \text {available }}$

The results for a system with $\eta_{e}=75 \%$ is plotted in Fig. 10 . This situation roughly corresponds to the tests made with HP temperatures around $130^{\circ} \mathrm{C}$ and $145^{\circ} \mathrm{C}$ presented in the experimental results section).

It may be seen that the optimum HP temperatures are roughly unaltered, but the total electric output is reduced as expected.

Although simplified, the aforementioned theoretical approach is useful to have a global insight into the influence of factors such as the temperature at which the heat exchange with the exhaust system takes place (the HP temperature), the heat harvesting efficiency and also the exhaust temperature, although the mass flow rate of gases has been kept constant in the analysis.

Page 7 of 13

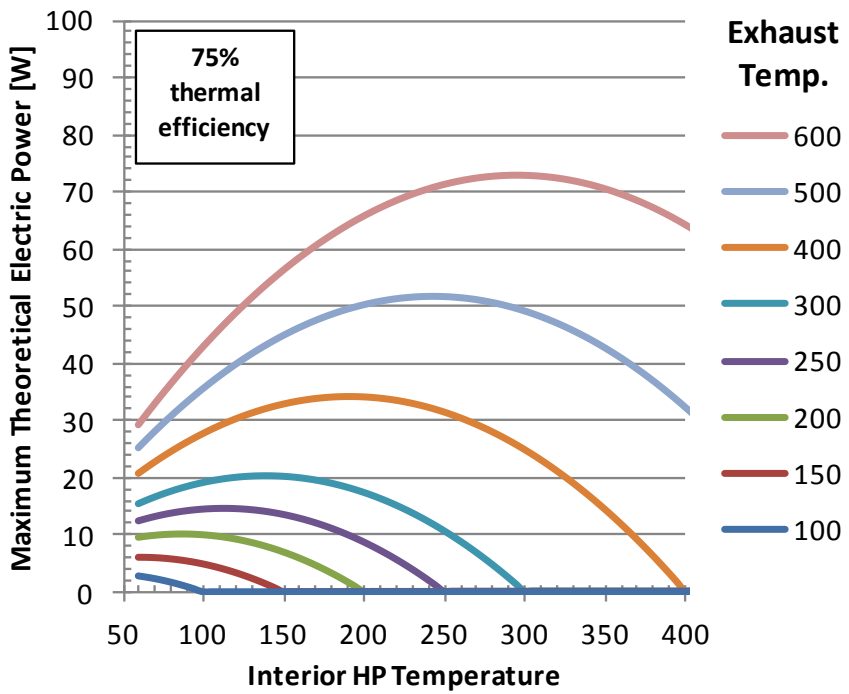

Figure 10. Electric power generated by a system with $75 \%$ thermal efficiency, as a function of HP temperature and Exhaust temperature

\section{Experimental Results}

To further assess the phenomena under study a set of experimental tests was performed with a proof-of-concept prototype for a range of $\mathrm{HP}$ temperatures between $100^{\circ} \mathrm{C}$ and $160^{\circ} \mathrm{C}$. The coolant flow was kept constant $(31 \pm 0.6 \mathrm{~g} / \mathrm{s})$ in all tests.

\section{$1 \mathrm{bar} / 100{ }^{\circ} \mathrm{C}$}

Fig. 11 displays the temperatures recorded during a test made with pressure of $1 \mathrm{bar}$, which resulted in an operating temperature around $100{ }^{\circ} \mathrm{C}$ (water boiling point for this pressure).

The $10 \mathrm{hp}$ diesel engine was connected to a hydraulic dynamometer and run at a stabilized speed of around 3500 rpm. The exhaust temperature (tagged "gases entry") can be seen here fluctuating between 200 and $250^{\circ} \mathrm{C}$ with the outlet gas (tagged "gases exit") stabilizing around $160^{\circ} \mathrm{C}$. It can be seen that the HP interior reaches the operating temperature rather quick, and completely stabilizes for the rest of the test.

The first condenser block to receive the heat is Block 3 (see Fig. 11 for block nomenclature), which is the lowest one along the heat pipe condensers region. A steep increase of the temperature of hot faces of the thermoelectric modules attached to this block (tagged "hot face Block 3") can be observed. This indicates that the prototype displays a rather low thermal resistance at the hot side temperatures of the modules are smoothly increasing. This is a result of the 
cooling water circuit being shared with the hydraulic brake circuit, which heats up during the test.
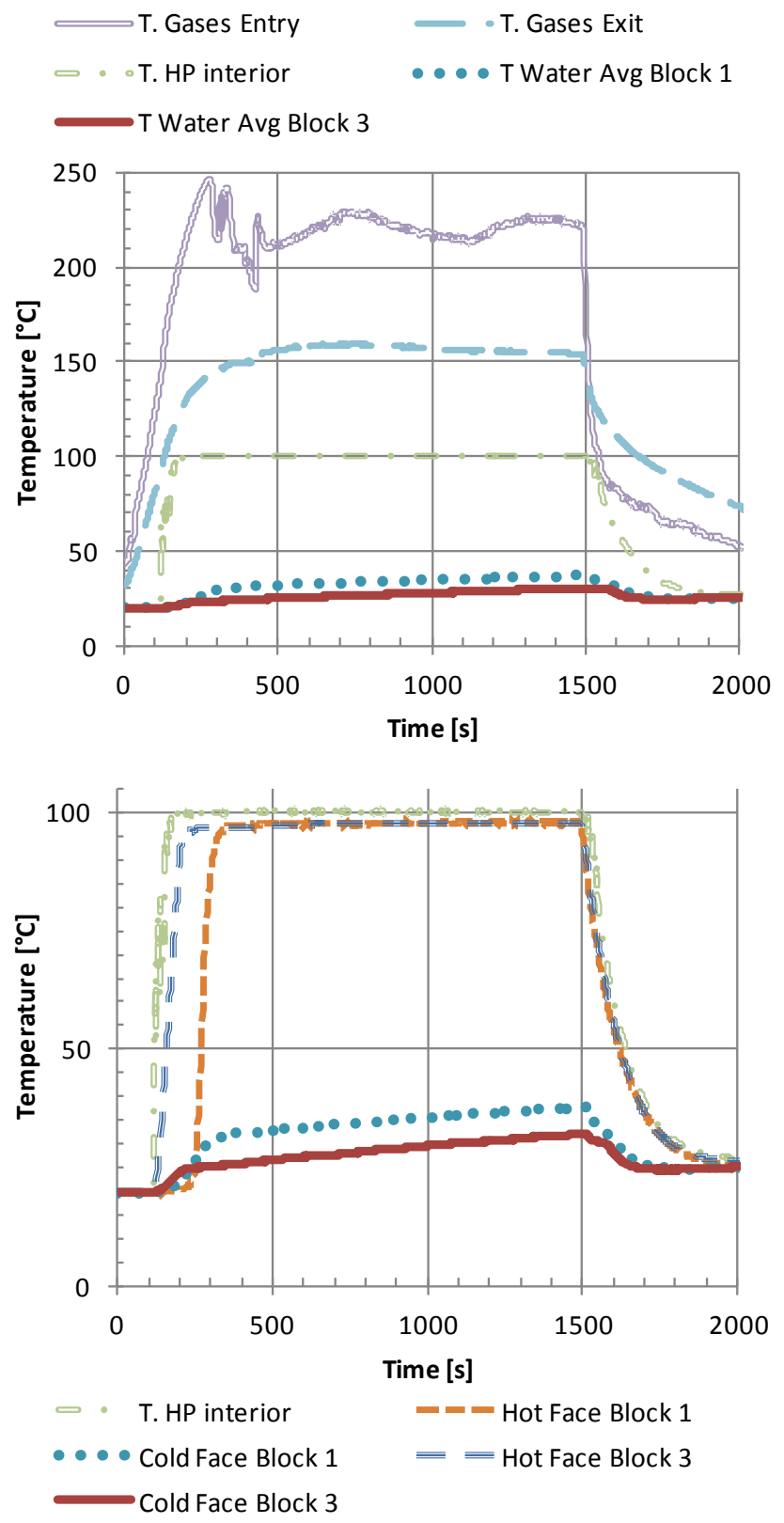

Figure 11. Temperature results for an HP pressure / temperature of $1 \mathrm{bar} / 100^{\circ} \mathrm{C}$

A specific curve in Fig. 12, the one tagged "Cup thermal power", is worthy of mentioning. It corresponds to the thermal power absorbed by the cup located between the condenser and the expansion tank. This cup consists on a concentric tube heat exchanger that uses the water of the cooling system. Its function is to absorb the excess heat that is not transferred across the modules. It avoids the migration of vapor to the expansion tank and the dry out of the evaporator in the event of excess thermal power at the evaporator. It starts absorbing heat around 500s after the beginning of the test.

Fig. 12 highlights the thermal powers of the three different blocks, as well as the excess heat cup. The powers are estimated by measuring the temperature difference of the coolant before and after each block. This increase yields the thermal power transmitted from the modules to the coolant by using the following expression:

$P_{\text {block_i }}=\dot{m}_{\text {coolant }} \cdot c_{p_{-} \text {coolant }} \cdot\left(T_{\text {cool_out_i }_{-}}-T_{\text {cool_in_i }_{-}}\right)$

It is interesting to note in Fig. 12 the cascade operation of the system. The following block only starts to be heated once the preceding block has achieved the full HP temperature. This is advantageous since heat dilution is avoided. It is therefore natural that, as seen in Fig. 12, the excess heat cup only enters operation once all three blocks are at their full operation.

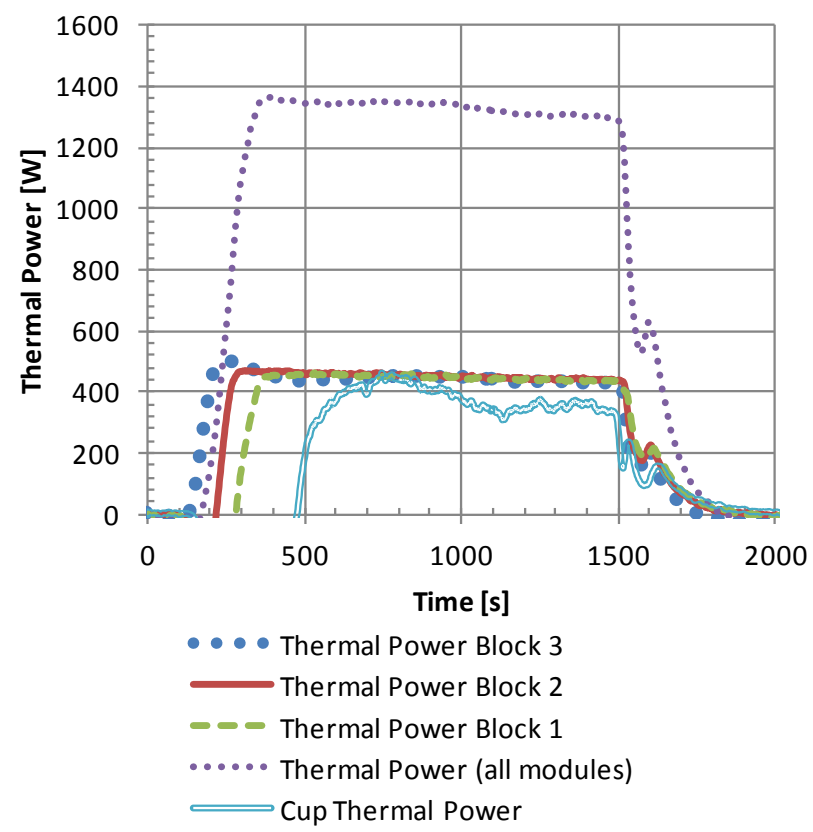

Figure 12. Thermal power results for an HP pressure / temperature of $1 \mathrm{bar} / 100^{\circ} \mathrm{C}$

The electric power output of the three blocks of the system is displayed in Fig. 13. There was a performance problem with block 2 that made it provide a slightly lower output than is was supposed. Apart this anomaly, the differences between the outputs of the three blocks have to do with the warming of the coolant as it passes through each block. Also, the slight decreasing trend of the curves has to do with the increase of the coolant circuit temperature, which is common to the engine brake circuit. Eventually, this factor gradually deprecated the available $\Delta \mathrm{T}$ and therefore the electric output. 


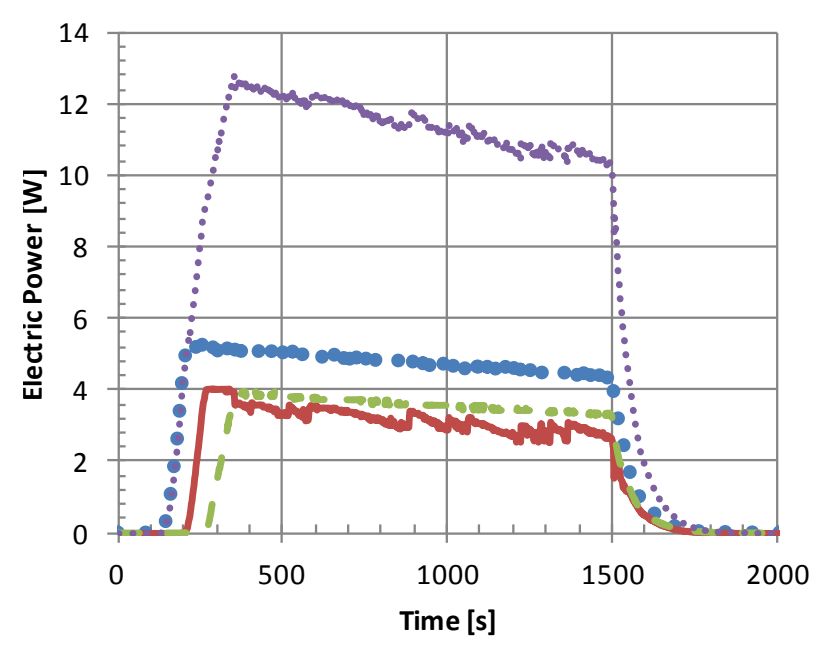

- - Electric Power Block $3 \longrightarrow$ Electric Power Block 2

- Electric Power Block 1 -.... Electric Power (total)

Figure 13. Electric power results for an HP pressure / temperature of $1 \mathrm{bar} / 100^{\circ} \mathrm{C}$

\section{$2.7 \mathrm{bar} / 130{ }^{\circ} \mathrm{C}$}

The next Figures refer to the test that provided the highest total electric output, corresponding to $130{ }^{\circ} \mathrm{C}$ of $\mathrm{HP}$ operating temperature.

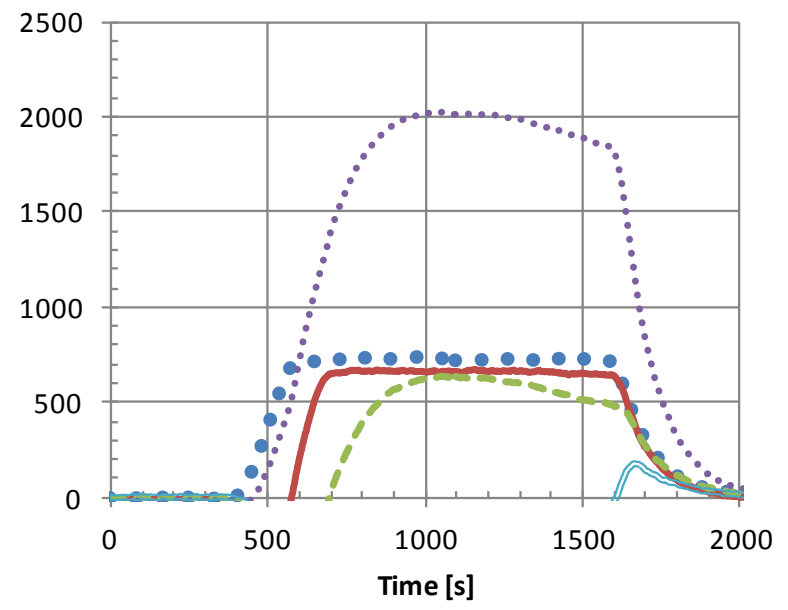

\footnotetext{
- - Thermal Power Block 3 Thermal Power Block 2

- Thermal Power Block 1 -.... Thermal Power (Total)

Cup Thermal Power
}

Figure 14. Thermal power results for an HP pressure / temperature of $2.7 \mathrm{bar} / 130^{\circ} \mathrm{C}$

These results are in line with the theoretical predictions previously described, where the maximum output for $300{ }^{\circ} \mathrm{C}$ exhaust temperature was around this value (recall Fig. 10). In this test the cascading start of the three blocks also happens, but slower. Achieving maximum output means that among the Page 9 of 13 four tests done this is the one that achieved the best compromise between TEG efficiency (increases with temperature increase) and available thermal power (decreases with temperature increase). Nevertheless, looking at Fig. 14 it can be seen that as the end of the test approaches, the available thermal power starts falling short for the full operation of the last block (Block 1).

\section{6 bar $/ 160^{\circ} \mathrm{C}$}

Fig. 15 shows the results for the highest HP temperature tested (around $160{ }^{\circ} \mathrm{C}$, achieved with an inner HP pressure around 6 bar).
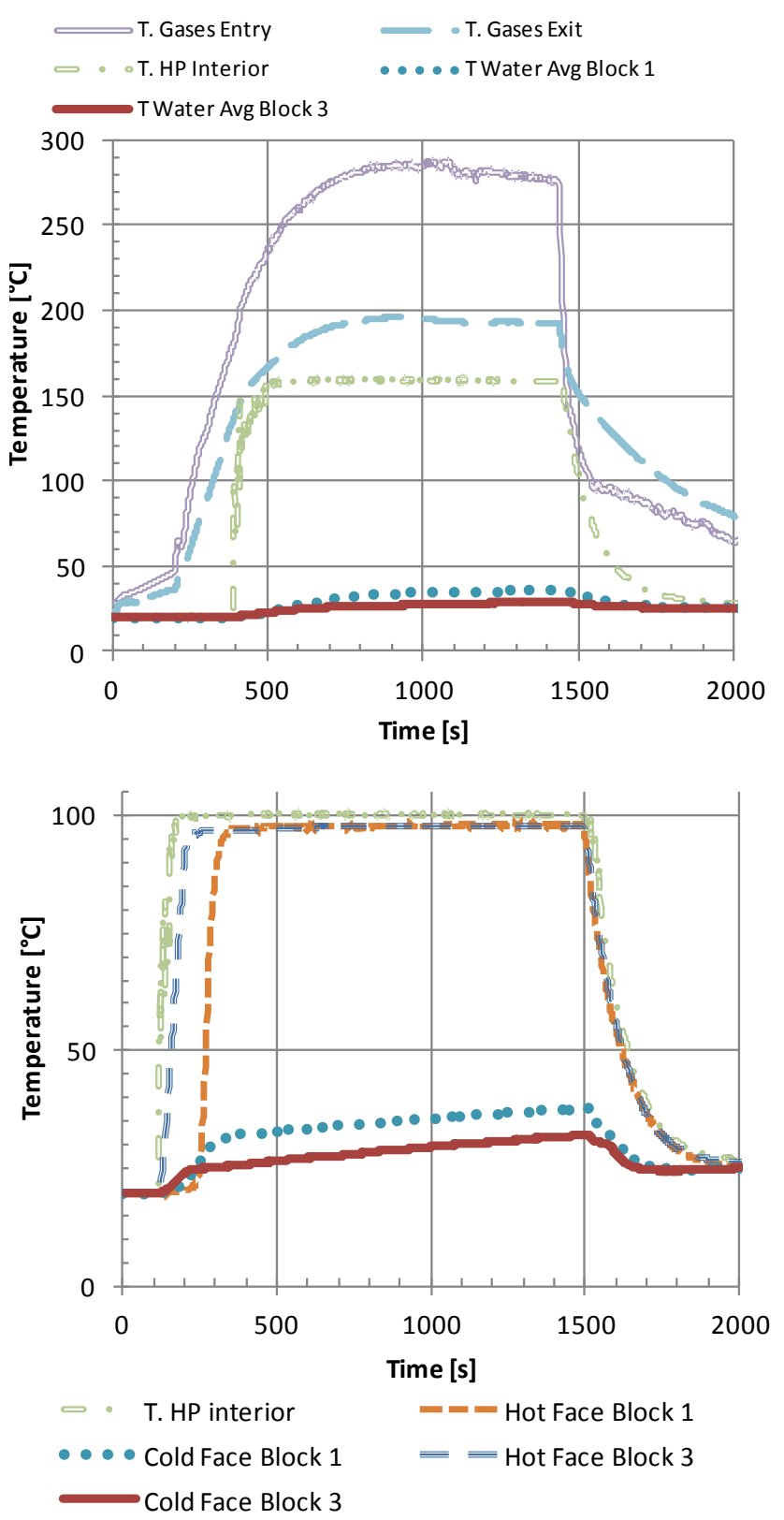

Figure 15. Temperature and electric / thermal power results for an $\mathrm{HP}$ pressure / temperature of $6 \mathrm{bar} / 160^{\circ} \mathrm{C}$ 
Clearly, here the available thermal power is only sufficient to fully activate Block 3, as seen in Fig. 16. Nevertheless, the exhaust exit temperature was still higher than the HP temperature, meaning that the efficiency of the heat exchanger could still be improved.

A strange phenomenon, notorious also in the previously described test, can be observed, in which the excess heat cup is briefly active as soon as the heat source is removed at the end of the test.

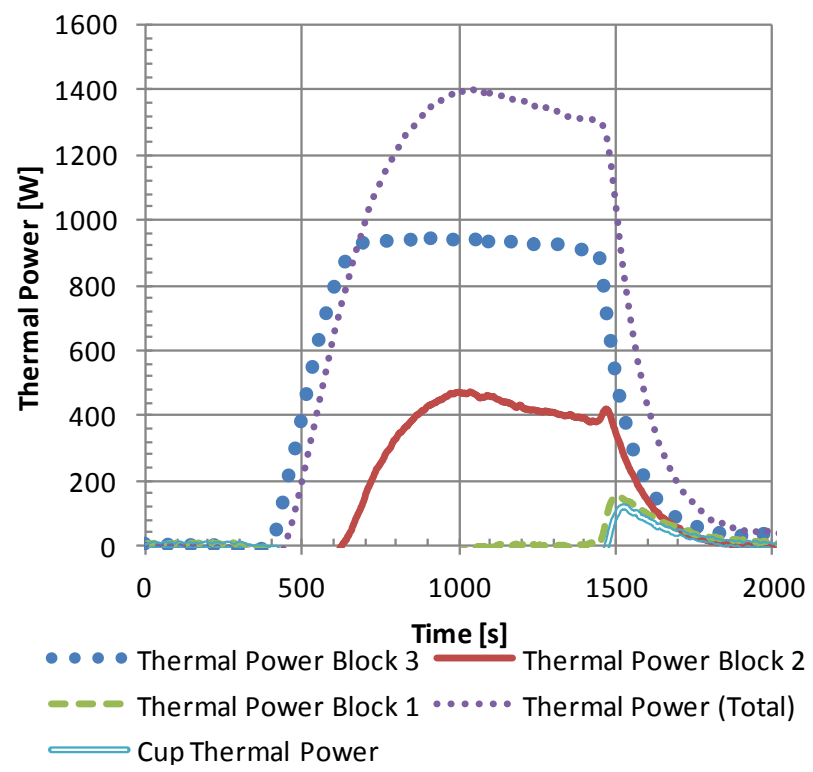

Figure 16. Thermal power results for an HP pressure / temperature of $6 \mathrm{bar} / 160^{\circ} \mathrm{C}$

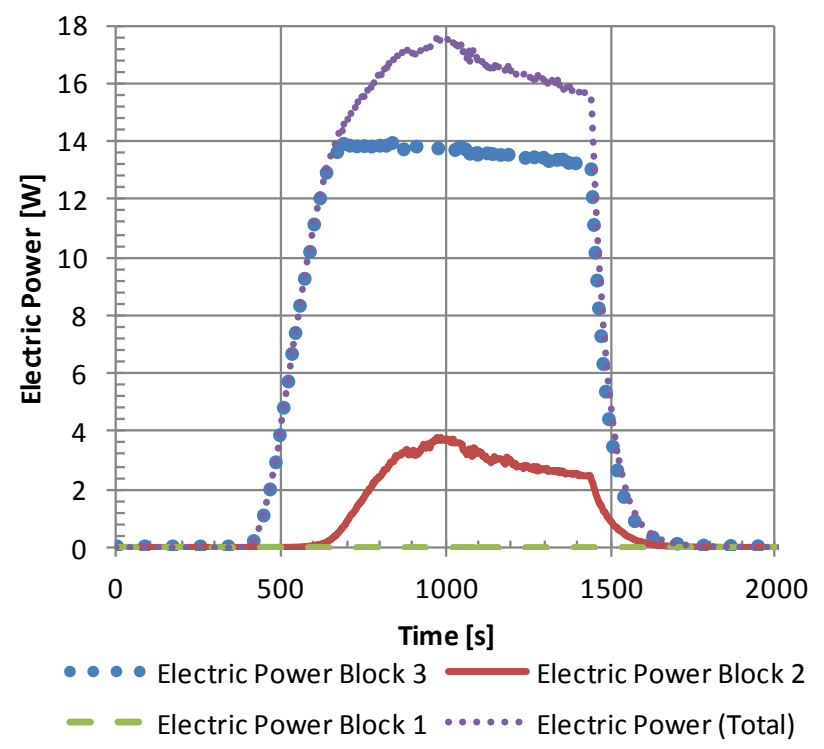

Figure 17. Electric power results for an HP pressure / temperature of 6 bar $/ 160^{\circ} \mathrm{C}$

Page 10 of 13

\section{Global results}

It seems useful to end the analysis by looking at the trends of the whole group of tests made, in terms of thermal power, open circuit voltage, electric power and electric efficiency of the system. The values on these plots are representative of the steady state operation.

Beginning with the thermal powers displayed in Fig. 18, it can be confirmed what already was noted earlier, of the cascade operation of the three blocks. The blocks are gradually activated depending on the available thermal power. This mode of operation is convenient as it avoids heat dilution. The cascade operation is a consequence of the variable conductance of the heat pipes used (VCHPs). As more power is supplied to the evaporator, a higher mass of vapor is generated reaching higher regions of the condenser as it pushes up the compressed air present inside the HP.
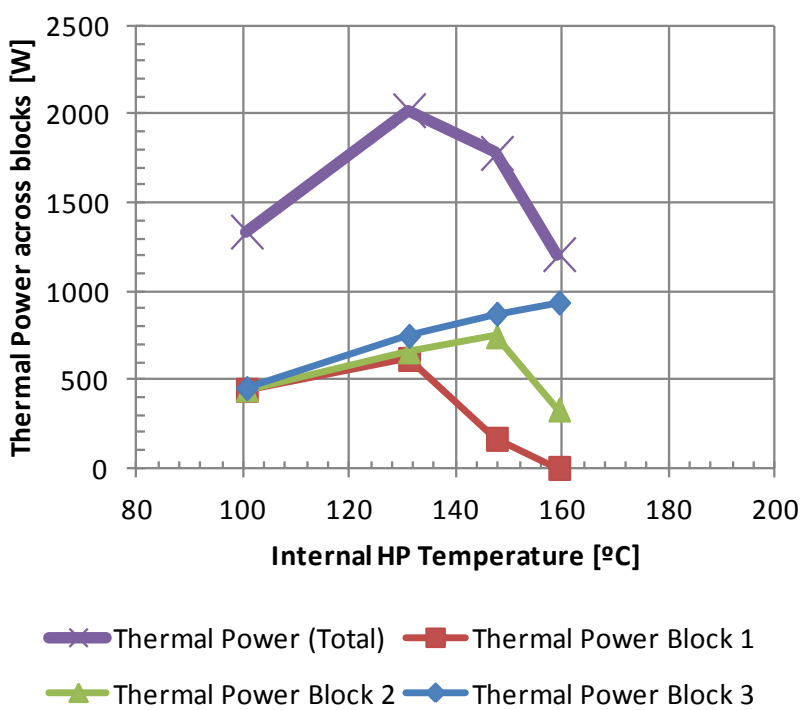

Figure 18. Steady State thermal power results for the whole $\mathrm{HP}$ pressure / temperature range tested

The response of Block 3 in terms of thermal power absorbed varies approximately linearly with the HP temperature. The open circuit voltage generated by Seebeck effect shown in Fig. 19 is rather proportional to the HP temperature, indicating a fairly stable Seebeck coefficient for this temperature range.

The electric power generated under near-to-steady state conditions is displayed in Fig. 20 for the whole test range. The values displayed were calculated based on the voltage measurements made to the several modules. In some of them the open circuit voltage was measured while in others a circuit with precision resistances was used. The value of the resistances was chosen so as to maximize power (ideally this resistance should equal the internal resistance of the modules). Since electric power depends on the square of the voltage, the 
differences between the power curves of the three blocks are more apparent than between voltage curves. The slight increase in coolant temperature as it sequentially cools each block has a mild effect on the power generated since this coolant warming slightly deprecates the temperature difference across the faces of the modules. This is a reason for the differences in power even when all three blocks are operating at full power.

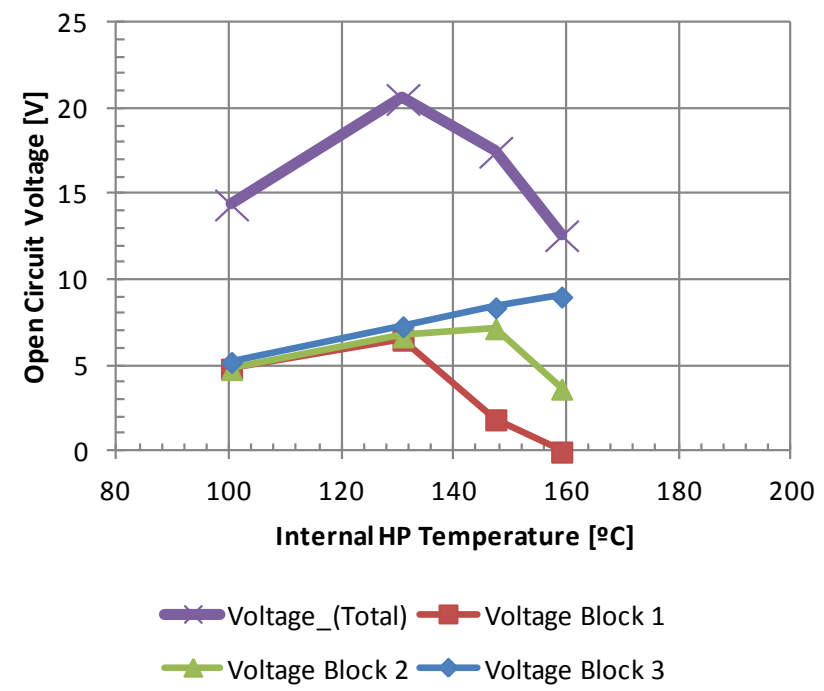

Figure 19. Steady State Open Circuit Voltage results for the whole HP pressure / temperature range tested
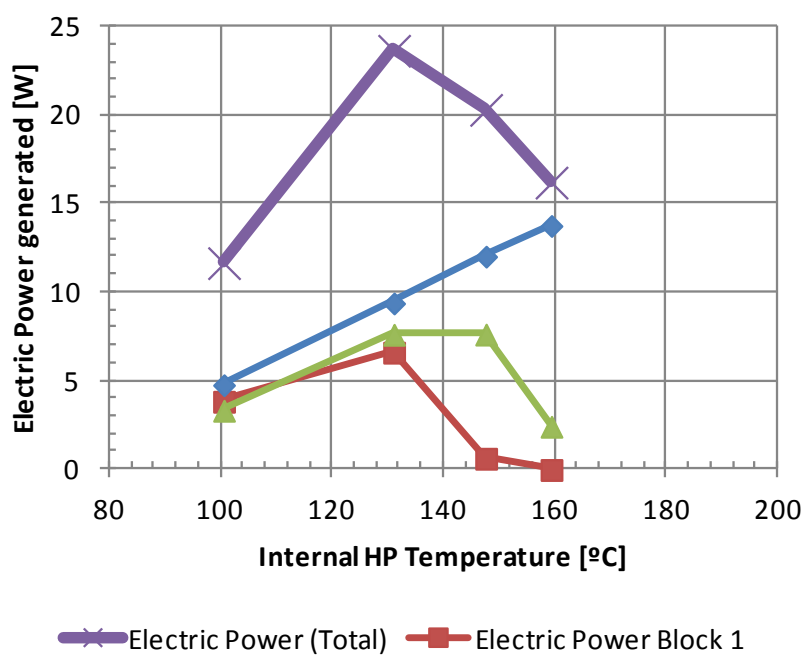

$\longrightarrow$ Electric Power Block $2 \leadsto$ Electric Power Block 3

Figure 20. Steady State Electric Power results for the whole $\mathrm{HP}$ pressure / temperature range tested
The last plot to be analyzed is the one displayed in Fig. 21 which refers to the electric efficiency, $\eta_{e}$, of the three different blocks of modules. The definition for this factor has been made in eq. 6. For Block 3, which is under full operation in all tests, $\eta_{e}$ is roughly linear with the HP temperature. For the theoretical analysis previously presented, there is interest to infer a mathematical relation between $\eta_{e}$ and the temperature differential $\left(\mathrm{T}_{\mathrm{HP}}-\mathrm{T}_{\text {coolant_avg }}\right)$ for use in equations 7 and 8 . For the measured global efficiency of the system, the thick purple curve presented in Fig. 21 , the following expression was obtained by linear regression:

$\eta_{e}=6.824 \cdot 10^{-5}\left(T_{H P}-T_{\text {coolant_avg }}\right)+4.146 \cdot 10^{-3}$

This linear relation was used to build the plots shown in Figures 9 and 10. In general, the efficiency of a thermoelectric device is not linear with temperature, but for this limited temperature range it is the indicated curve fit.

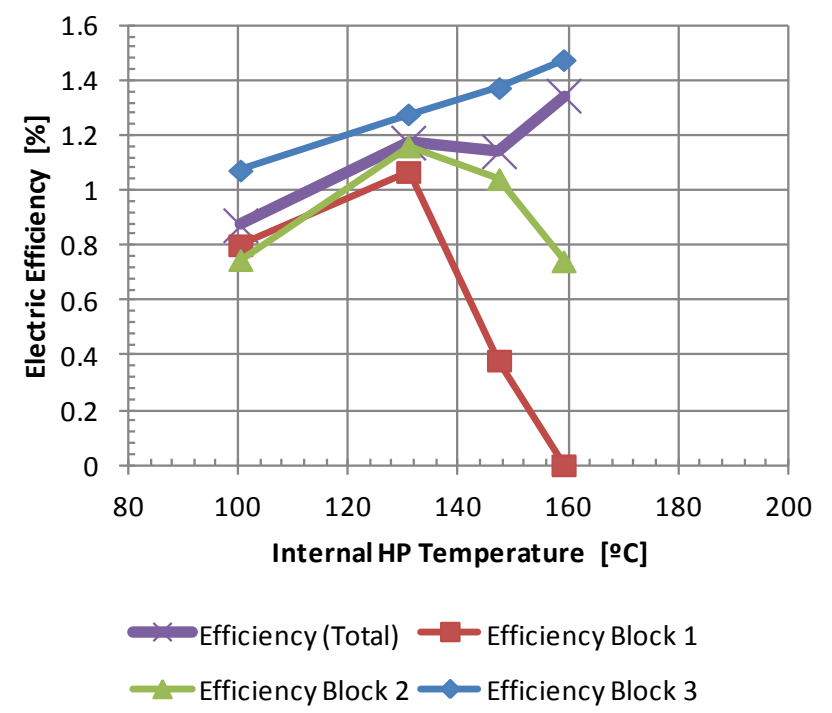

Figure 21. Steady State Electric efficiency results for the whole HP pressure / temperature range tested

\section{CONCLUSIONS}

The present work assessed both theoretically and experimentally the influence of the heat exchange operating temperature on the operation of exhaust heat recovery thermoelectric generators incorporating temperature control through variable conductance heat pipes.

Theoretical expressions were derived to estimate the optimum $\mathrm{HP}$ temperature for maximizing the electric output of a thermoelectric generator as a function of exhaust temperature.

A small capacity Proof-of-Concept thermoelectric generator with 3 blocks of 4 thermoelectric modules was built and tested 
for a range of $\mathrm{HP}$ operating temperatures $\left(100{ }^{\circ} \mathrm{C}-160^{\circ} \mathrm{C}\right)$. A small ( $9 \mathrm{hp}$ ) Diesel engine with low exhaust temperatures $\left(200{ }^{\circ} \mathrm{C}-300^{\circ} \mathrm{C}\right)$ was used. This was done in order to illustrate the capability of these generators to operate even with low powers / temperatures, but the concept is still valid for bigger systems with higher installed powers.

Both the predictions and the tests showed that although the efficiency of the modules increases with the operating temperature, nevertheless the increasing the HP temperature beyond a certain limit eventually causes the degradation of the electric generation due to the reduction of the usable/available exhaust energy. Nevertheless, a high HP operating temperature will be limitative for performance mainly in cases where low exhaust temperature and low engine power are present. Both predictions and tests recorded an optimum HP temperature around $130{ }^{\circ} \mathrm{C}$ for the generator under analysis and for the engine operating conditions tested.

Despite the still low (but increasing) efficiencies of commercially available thermoelectric modules, the studied concept based on temperature controlled heat transfer through heat Pipes showed several advantages over bypass/wastegate systems currently deployed in existing exhaust heat recovery systems. Evaporative-based heat transfer allows for very low thermal resistance. VCHPs provide heat conversion (by temperature downgrade) rather than heat rejection in excess power events as in the case of bypass systems. There is no heat dilution due to the cascade operation as well as passive protection against overheating. The advances in thermoelectric material will further boost the usefulness of the approaches studied.

\section{REFERENCES}

1. Bell, L., "Cooling, heating, generating power, and recovering waste heat with thermoelectric systems", Science, 321, pp. 1457-1461, 2008.

2. European Commission, EU Climate and Energy Package, 2010, available at http://ec.europa.eu/clima/documentation/package/docs/cli mate package en.pdf, (accessed October 25th, 2012).

3. Environmental Protection Agency (EPA), Department of Transportation (DOT), National Highway Traffic Safety Administration (NHTSA). 2017 and Later Model Year Light-Duty Vehicle Greenhouse Gas Emissions and Corporate Average Fuel Economy Standards -Final Rule. Federal Register / Vol. 77, No. 199 / Monday, October 15, 2012 / Rules and Regulations. available at http://www.nhtsa.gov/staticfiles/rulemaking/pdf/cafe/201 7-25_CAFE_Final_Rule.pdf (accessed October 25th, 2012).

4. Martins, J., "Motores de Combustão Interna", 4th edition (revised and extended, in Portuguese), Publindustria, Porto, Portugal, ISBN: 978-989-723-033-2, 2013.
5. Heywood, J., Internal Combustion Engine Fundamentals, McGraw Hill, 1988.

6. Ribeiro, B. and Martins, J., "Direct Comparison of an Engine Working under Otto, Miller and Diesel cycles: Thermodynamic Analysis and Real Engine Performance”, SAE Technical Paper 2007-01-0261, 2007.

7. Martins, J. J.G., Uzuneanu, K., Ribeiro, B. and Jasansky, O., "Thermodynamic Analysis of an Over-Expanded Engine", SAE Technical Paper 2004-01-0617, included in 'Modeling of Spark Ignition Engines', edited by SAE (ISBN Number: 0-7680-1366-6), 2004.

8. Hung, T. C., Shai, T. Y. and Wang S. K. "A review of organic rankine cycles (ORCs) for the recovery of lowgrade waste heat", Energy, Elsevier, 22-7, pp. 661-667, 1997.

9. Weerasinghe, W., Stobart, R., Hounsham, S., "Thermal efficiency improvement in high output diesel engines a comparison of a Rankine cycle with turbo-compounding", Appl Thermal Eng, Elsevier, 30(14-15), pp. 2253-2256, 2010.

10. Vining, C.B. "An inconvenient truth about thermoelectrics", Nature Materials, 8, February 2009.

11. Min, Gao and Rowe, D. M., "Conversion Efficiency of Thermoelectric Combustion Systems", IEEE Transactions on Energy Conversion, 22- 2, June, 2007.

12. Mori, M., Yamagami, T., Sorazawa, M., Miyabe et al., "Simulation of Fuel Economy Effectiveness of Exhaust Heat Recovery System Using Thermoelectric Generator in a Series Hybrid", SAE Technical paper 2011-01-1335.

13. BMW group corporate communications, "Press Release: Looking for the next gram”, 28 August 2011, available at: https://www.press.bmwgroup.com/pressclub/p/pcgl/down load.html?textId=144138\&textAttachmentId=174413 (accessed October $25^{\text {th }}$ 2012).

14. Dresselhaus, M.S., Chen, G., Tang, M.Y., Yang, RG, et al., "New Directions for Low-Dimensional Thermoelectric Materials". Adv. Mater., 19 (2007): 1043 1053. doi: 10.1002/adma.200600527

15. Gonçalves, L.M., Martins, J., Antunes, J., Rocha, R. and Brito, F. P.,'Heat-Pipe Assisted Thermoelectric Generators for Exhaust Gas Applications”, ASME 2010 International Mechanical Engineering Congress \& Exposition, November, 12-18, Vancouver, British Columbia, Canada, 2010.

16. Martins, J., Brito, F.P., Goncalves, L.M., Antunes, J., "Thermoelectric Exhaust Energy Recovery with Temperature Control through Heat Pipes", SAE Technical Paper 2011-01-0315, 2011

17. Brito, F.P., Martins, J., Goncalves, L.M., Sousa, R., "Modelling of Thermoelectric Generator with Heat Pipe Assist for Range Extender Application", 37th Annual Conference of the IEEE Industrial Electronics Society (IECON 2011), November 7-10th, Melbourne, Australia, 2011

18. Brito, Francisco P., Martins, Jorge, Sousa, Rui, Gonçalves, L.M., "Temperature controlled Exhaust Heat Thermoelectric Generation", SAE International Journal of 
Passenger Cars - Electronic and Electrical Systems, Vol 5 No (2), 2012.

19. Reay, David and Kew, P., "Heat Pipes, Theory, Design and Applications", Butterworth-Heinemann, Elsevier, 2006.

20. Goldsmid, H. J., "CRC Handbook of Thermoelectrics", London CRC Press, edited by D.M. Rowe, 1987.

\section{CONTACT INFORMATION}

Francisco P. Brito is a Post-Doctoral researcher at CT2M (Center for Mechanics and Materials Technologies) at Mechanical Engineering Department of the University of Minho (Guimaraes, Portugal) and Assistant Professor at ISEP (Porto, Portugal). Contact: francisco@dem.uminho.pt

Jorge Martins is a researcher at CT2M (Center for Mechanics and Materials Technologies) and an Associate Professor at the Mechanical Engineering Department of the University of Minho at Guimaraes, Portugal, where he is head of the I.C. Engines Laboratory. Contact: jmartins@ dem.uminho.pt

Luís M. Gonçalves is a researcher from Algoritmi Centre and Auxiliar Professor at the Industrial Electronics Department of the University of Minho at Guimaraes, Portugal. Contact: lgoncalves@dei.uminho.pt

Diogo Sousa is an MSc graduate and Nuno Antunes is an MSc student at the Industrial Electronics Department of the
University of Minho at Guimaraes, Portugal. Contacts: diogo.amso@gmail.com; nunoant86@hotmail.com

\section{ACKNOWLEDGMENTS}

This research project is funded by Project MIT-Pt/EDAMSMS/0030/2008 supported by the MIT Portugal Program and FEDER funds through the Programa Operacional Factores de Competitividade - COMPETE and National Funds through FCT - Foundation for Science and Technology. Francisco P. Brito benefits from MIT Portugal EDAM post-doctoral grant SFRH/BPD/51048/2010.

\section{DEFINITIONS/ABBREVIATIONS}

HP

ICE

TE

TEG

VCHP
Heat Pipe

Internal Combustion

Engine

Thermoelectric

Thermoelectric Generator

Variable Conductance

Heat Pipe 